\title{
Quantifying light response of photosynthesis: addressing the long-standing limitations of non-rectangular hyperbolic model
}

\author{
Z.P. YE*, S.H. DUAN ${ }^{* *}$, X.M. CHEN ${ }^{* * *}$, H.L. DUAN", C.P. GAO ${ }^{\# \#, ~ H . J . ~ K A N G ~}{ }^{\# \#, \S, ~ T . ~ A N *, ~}$ \\ and S.X. ZHOU ${ }^{\S,+}$ \\ Maths \& Physics College, Jinggangshan University, 343009 Ji'an, China* \\ School of Life Sciences, Jinggangshan University, 343009 Ji'an, China** \\ Soil Fertilizer and Environmental Resources Institute, Jiangxi Academy of Agricultural Sciences, 330200 Nanchang, \\ China $^{* * *}$ \\ Jiangxi Provincial Key Laboratory for Restoration of Degraded Ecosystems \& Watershed Ecohydrology, Nanchang \\ Institute of Technology, 330099 Nanchang, China \\ College of Grassland Resources and Environment, Key Laboratory of Grassland Resources of the Ministry \\ of Education, Key Laboratory of Forage Cultivation, Processing and High Efficient Utilization of the Ministry \\ of Agriculture and Rural Affairs, Inner Mongolia Autonomous Region Key Laboratory of Grassland Management \\ and Utilization, Inner Mongolia Agricultural University, 010011 Hohhot, China ${ }^{\#}$ \\ Wenzhou Academy of Agricultural Sciences, 325006 Wenzhou, China ${ }^{\# \#}$ \\ Southern Zhejiang Key Laboratory of Crop Breeding, 325001 Wenzhou, China ${ }^{s}$ \\ The New Zealand Institute for Plant and Food Research Limited, Hawke's Bay 4130, New Zealand ${ }^{\S}$
}

\begin{abstract}
Light intensity $(I)$ fluctuates rapidly and is the most important environmental factor affecting photosynthesis. Accurate characterization of light-response curve of leaf-scale photosynthesis $\left(P_{\mathrm{N}}-I\right.$ curve) is fundamental for understanding $P_{\mathrm{N}}-I$ relations at the whole-plant and ecosystem scales. A robust $P_{\mathrm{N}}-I$ model should be accurate in reproducing $P_{\mathrm{N}}-I$ curves over light-limited, light-saturated, and photoinhibitory $I$ levels, and ideally returning key quantitative traits defining the curves, including initial slope of increase $(\alpha)$, dark respiration rate $\left(R_{\mathrm{D}}\right)$, the maximum net photosynthetic rate $\left(P_{\mathrm{Nmax}}\right)$, and the corresponding saturation intensity $\left(I_{\mathrm{sat}}\right)$. We need to improve a model reproduction of (1) $P_{\mathrm{N}}-I$ responses over low $I$ levels and (2) the widely reported decline of $P_{\mathrm{N}}$ at photoinhibitory $I$ levels. Our observationmodelling comparison, shown by the widely used non-rectangular hyperbolic model, led to (1) underestimation of $R_{\mathrm{D}}$, (2) overestimation of $P_{\mathrm{Nmax}}$, and (3) failure in reproducing the photoinhibitory response when $I$ surpassed the

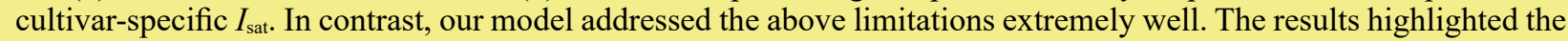
accuracy and robustness of our model, especially in (1) returning key traits defining the curve and (2) reproducing the curve over both low $\left[\right.$ i.e., $0-50 \mu \mathrm{mol}$ (photon) $\mathrm{m}^{-2} \mathrm{~s}^{-1}$ ] and photoinhibitory $I$ levels (i.e., beyond $I_{\text {sat }}$ ).
\end{abstract}

Keywords: light-response curve; maximum net photosynthetic rate; model; photoinhibition; photosynthesis; saturation light intensity.

\section{Highlights}

- Ye model performs better than $\mathrm{NH}$ model in obtaining the dark respiration rate

- Ye model is better than NH model in determining the maximum net photosynthetic rate

- Ye model performs better than NH model in reproducing the photoinhibitory response
Received 26 May 2020

Accepted 1 February 2021

Published online 26 February 2021

\section{${ }^{+}$Corresponding author}

phone: 64-69758911

e-mail: shuangxi.zhou@plantandfood.co.nz

Abbreviations: $I$ - light intensity; $I_{\mathrm{c}}-$ light-compensation point; $I_{\mathrm{sat}}-$ saturation intensity; NH model - non-rectangular hyperbolic model; $P_{\mathrm{N}}-$ net photosynthetic rate; $P_{\mathrm{Nmax}}-$ maximum net photosynthetic rate; $R_{\mathrm{D}}$ - dark respiration rate; $\alpha$ - initial slope; $\theta$ - convexity of the curve.

Acknowledgements: This work was financially supported by the National Natural Science Foundation of China $(31960054,41961005)$, Jiangxi Special Fund for Agro-Scientific Research in the Collaborative Innovation (JXXTCX2015001-005), and the Innovative Research Team of the Ministry of Education of China (IRT_17R59).

Conflict of interest: The authors declare that they have no conflict of interest. 


\section{Introduction}

Light intensity (I) changes rapidly and is usually viewed as the most dynamic and significant environmental variable affecting photosynthesis $\left(P_{\mathrm{N}}\right)($ Knapp and Smith 1987). Plants in most ecosystems experience rapid short-term variability in light (Smith et al. 1989), which can cause continual transition of $P_{\mathrm{N}}$ throughout the growing season (Knapp and Smith 1990). Accurate and rapid characterization of the light-response curve of photosynthesis $\left(P_{\mathrm{N}}-I\right.$ curve) at leaf scale can facilitate assessment of the plant's potential photosynthetic capacity over a wide range of ambient light intensities (Ögren and Evans 1993), which is fundamental for $P_{\mathrm{N}}-I$ modelling at the whole-plant and ecosystem scales.

The $P_{\mathrm{N}}-I$ curve is usually characterized by a collection of quantitative traits, including the initial slope of increase $(\alpha)$, the maximum net photosynthetic rate $\left(P_{\mathrm{Nmax}}\right)$, and the corresponding saturation light intensity $\left(I_{\text {sat }}\right)$, lightcompensation point $\left(I_{\mathrm{c}}\right)$, and dark respiration rate $\left(R_{\mathrm{D}}\right)$. These quantitative traits can (1) inform larger-scale models on the species-specific and/or plant functional type-specific adaptation to different light regimes and (2) reflect the underlying biophysical, biochemical, and metabolic processes that regulate plant photosynthesis and/or vegetation fluxes under different environmental conditions (Thornley 1998, Aspinwall et al. 2011, Wargent et al. 2011, Xu et al. 2012a,b; Mayoral et al. 2015, Wang et al. 2015, Yao et al. 2017).

The $P_{\mathrm{N}}-I$ curve is usually sectioned into three distinct parts depending on $I$ levels - light-limited, light-saturated, and photoinhibitory regions (Ralph and Gademann 2005). $P_{\mathrm{N}}$ increases with the increasing $I$ over the light-limited region until $I$ reaches $I_{\text {sat }}$, after which $P_{\mathrm{N}}$ decreases with the increasing $I$ due to photoinhibition induced by high light intensity (Ralph and Gademann 2005, Ye et al. 2013). A few models have been developed to characterize $P_{\mathrm{N}}-I$ curves and extract key quantities for higher plants, such as the rectangular hyperbolic model (Baly 1935), the Smith's equation (Smith 1936), the Webb's, Newton's, and Starr's equation (Webb et al. 1974), the non-rectangular hyperbolic model (Ögren and Evans 1993, Thornley 1976, 1998), the negative exponential equations (Bassman and Zwier 1991, Posada et al. 2009), biochemical model of Farquhar et al. (1980), and so on. Among these models, the non-rectangular hyperbolic model (hereafter, $\mathrm{NH}$ model) is the most widely used model in characterizing $P_{\mathrm{N}}-I$ curve over light-limited and light-saturated regions, estimating quantitative traits, such as $\alpha, P_{\mathrm{Nmax}}, I_{\mathrm{c}}$, and $R_{\mathrm{D}}$ (Zhu et al. 2004, Messinger et al. 2006, Gomes et al. 2006, Leakey et al. 2006, Koyama and Kikuzawa 2010, Aspinwall et al. 2011, Calama et al. 2013, Wang et al. 2014, Raj et al. 2016).

It remains uncertain to what extent each of the above models can be used to reproduce accurately the $P_{\mathrm{N}}-I$ curves from $0 \mu \mathrm{mol}$ (photon) $\mathrm{m}^{-2} \mathrm{~s}^{-1}$ to high $I$ levels and realistically fit key quantitative traits. For instance, the $\mathrm{NH}$ model, the rectangular hyperbola model, and the exponential equation had been reported to produce biased estimates of $R_{\mathrm{D}}$ (dos Santos et al. 2013) and behave poorly in reproducing the decline of $P_{\mathrm{N}}$ at the photoinhibitory region (Prado and Moraes 1997, Yu et al. 2002, Leakey et al. 2006, Aspinwall et al. 2011, Xu et al. 2012a, dos Santos et al. 2013, Mayoral et al. 2015, Ogawa 2015, Bellucco et al. 2017). Meanwhile, overestimation of $P_{\mathrm{Nmax}}$ by $\mathrm{NH}$ model had been widely reported (Calama et al. 2013, dos Santos et al. 2013, Ježilová et al. 2015, Mayoral et al. 2015, Ogawa 2015, Park et al. 2016, Bellucco et al. 2017, Quiroz et al. 2017, Poirier-Pocovi et al. 2018). The $P_{\mathrm{N}}-I$ model developed by Ye (2007) and Ye et al. (2013) (hereafter, Ye model), using a nonasymptotic function, has been increasingly reported on its advantage over NH model in returning accurate $P_{\text {Nmax }}$ value and the corresponding $I_{\text {sat }}$ value (Ye 2007, Lobo et al. 2013, Ye et al. 2013, Martínez-García et al. 2017, Shimada et al. 2017, Liu et al. 2018).

Essentially, a robust $P_{\mathrm{N}}-I$ model should accurately reproduce the leaf-scale $P_{\mathrm{N}}$ responses across all $I$ levels. The model performance at low $I$ levels is of significance for validating uncertainties of vegetation fluxes. This is due to the fact that majority of vegetation worldwide is subject to at least partial shade (Keenan and Niinemets 2017), and also the small flux such as $R_{\mathrm{D}}$ plays an important role when scaling-up at larger scales (Hanson et al. 2016). On the other hand, an ideal $P_{\mathrm{N}}-I$ model should also accurately reproduce the decline of $P_{\mathrm{N}}$ over the photoinhibitory region (i.e., beyond $I_{\text {sat }}$ ), which is important for modelling fluxes of vegetation in high-light environments.

Before incorporating leaf-scale $P_{\mathrm{N}}-I$ model into plantand ecosystem-scale models, one important but largely ignored step is to evaluate the behavior of potentially promising leaf-scale models over a wide range of light intensities - especially, the model representation over low $I$ levels [i.e., $0-50 \mu \mathrm{mol}$ (photon) $\mathrm{m}^{-2} \mathrm{~s}^{-1}$ ] and photoinhibitory region (i.e., beyond $I_{\text {sat }}$ ). For instance, experiment-based studies validating the performance of $\mathrm{NH}$ model at the low end [i.e., close to $0 \mu \mathrm{mol}$ (photon) $\mathrm{m}^{-2} \mathrm{~s}^{-1}$ ] and high end [i.e., close to 2,000 $\mu \mathrm{mol}$ (photon) $\mathrm{m}^{-2} \mathrm{~s}^{-1}$ ] of $I$ levels are scarce. The objective of this study was to compare the performance of Ye model vs. the most widely used $\mathrm{NH}$ model in reproducing $P_{\mathrm{N}}-I$ curve over light-limited, light-saturated, and photoinhibitory regions, through evaluating the model behavior over $I$ levels from 0 to $2,000 \mu \mathrm{mol}$ (photon) $\mathrm{m}^{-2} \mathrm{~s}^{-1}$ against experimental observations on three rice (Oryza sativa L.) cultivars.

\section{Materials and methods}

Description of NH model and Ye model: In brief, the NH model characterizes the $P_{\mathrm{N}}-I$ relationship as follows (Thornley 1976, 1998; Ögren and Evans 1993):

$$
P_{\mathrm{N}}=\frac{\alpha I+P_{\mathrm{Nmax}}-\sqrt{\left(\alpha I+P_{\mathrm{Nmax}}\right)^{2}-4 \theta \alpha I P_{\mathrm{Nmax}}}}{2 \theta}-R_{\mathrm{D}}
$$

where $P_{\mathrm{N}}$ is net photosynthetic rate, $I$ is light intensity, $P_{\text {Nmax }}$ is the maximum net photosynthetic rate, $\alpha$ is the initial slope of $P_{\mathrm{N}}-I$ curve, $\theta$ is the convexity of the curve 
(dimensionless), and $R_{\mathrm{D}}$ is dark respiration rate.

The first order derivative of Eq. 1 is as follows:

$$
\frac{d P_{\mathrm{N}}}{d I}=\frac{\alpha}{2 \theta}\left[1-\frac{\left(\alpha I+P_{\mathrm{N} \max }\right)-2 \theta P_{\mathrm{N} \max }}{\sqrt{\left(\alpha I+P_{\mathrm{N} \max }\right)^{2}-4 \theta \alpha I P_{\mathrm{N} \max }}}\right]
$$

where $d P_{\mathrm{N}} / d I$ equals to $\alpha$ when $I$ is zero, and $d P_{\mathrm{N}} / d I>0$ when $I>0$. Thus Eq. 1 is an asymptote which cannot be directly used to calculate the $I_{\text {sat }}$.

The Ye model characterizes the $P_{\mathrm{N}}-I$ relationship as follows (Ye 2007, Ye et al. 2013):

$$
P_{\mathrm{N}}=\alpha \frac{1-\beta I}{1+\gamma I} I-R_{\mathrm{D}}
$$

where $\alpha$ is the initial slope of $P_{\mathrm{N}}-I$ curve, $R_{\mathrm{D}}$ is dark respiration rate, and $\beta$ and $\gamma$ are the photoinhibition coefficient and saturation coefficient, respectively (Ye et al. 2013).

The first order derivative of Eq. 3 is as follows:

$$
\frac{d P_{\mathrm{N}}}{d I}=\alpha \frac{1-2 \beta I-\beta \gamma I^{2}}{(1+\gamma I)^{2}}
$$

where $d P_{\mathrm{N}} / d I$ decreases with increasing $I . d P_{\mathrm{N}} / d I$ equals to $\alpha$ when $I$ is zero, and $d P_{\mathrm{N}} / d I$ equals to zero when $I$ reaches $I_{\text {sat }} d P_{\mathrm{N}} / d I$ will be negative when $I$ surpasses $I_{\text {sat }}$, which is a key difference between Eq. 3 and Eq. 1.

$I_{\text {sat }}$ can be calculated when $d P_{\mathrm{N}} / d I=0$, as follows:

$$
I_{\mathrm{sat}}=\frac{\sqrt{(\beta+\gamma) / \beta}-1}{\gamma}
$$

The maximum net photosynthetic rate $\left(P_{\mathrm{N} \max }\right)$ can be calculated as follows:

$$
P_{\text {Nmax }}=\alpha\left(\frac{\sqrt{\beta+\gamma}-\sqrt{\beta}}{\gamma}\right)^{2}-R_{\mathrm{D}}
$$

Plant materials and growth conditions: Seeds of three rice cultivars (Jifengyou1326, Wufengyou1326, and JR1326) were provided by the Rice Research Institute of Jiangxi Academy of Agricultural Sciences. Seeds of the three cultivars were placed within Petri plates on two layers of Whatman $\mathrm{N}^{\circ} 5$ filter paper rinsed with $7 \mathrm{ml}$ of carbendazim $(0.025 \%, \mathrm{v} / \mathrm{v})$ at $26^{\circ} \mathrm{C}$ in darkness until emergence of the radicle. Seedlings were transplanted to 0.5-L plastic pots, containing sterile organic soil extract as substrate. At the four-leaf stage, 20 plants of each rice accession were transferred to 4-L pots and kept in a greenhouse under a $26 / 17^{\circ} \mathrm{C}$ diurnal temperature cycle and well-watered conditions for $12 \mathrm{~d}$. Afterwards, plants were transferred into the botanical garden of Jinggangshan University and grown in the open air under well-watered conditions for one month.

$P_{\mathrm{N}}-\boldsymbol{I}$ curve measurement and model fitting: At the filling stage, $P_{\mathrm{N}}-I$ curves of flag leaves were measured for three plants of each rice cultivar $(n=3)$ using a portable system ( $\mathrm{Li}$-Cor 6400; Li-Cor Inc., Lincoln, NE, USA). All measurements were performed between 9:00 and 16:00 h, with consistent cuvette parameters set up as follows: flow rate as $400 \mu \mathrm{mol} \mathrm{s} \mathrm{s}^{-1}$, leaf temperature as $30.5^{\circ} \mathrm{C}$, and relative humidity as $65 \%$. Measurements were conducted on sunny days between 1 and 9 September, 2014. Before each measurement, the leaf was acclimated to irradiance of $2,000 \mu \mathrm{mol}$ (photon) $\mathrm{m}^{-2} \mathrm{~s}^{-1}$ for $30 \mathrm{~min}$. $P_{\mathrm{N}}-I$ curve measurements were conducted in accordance to a descending order of $I$ levels: 2,$000 ; 1,800 ; 1,600$; 1,$400 ; 1,200 ; 1,000 ; 800,600,400,200,100,50$, and $0 \mu \mathrm{mol}\left(\right.$ photon) $\mathrm{m}^{-2} \mathrm{~s}^{-1}$. At each $I$ level, leaf gas exchange was monitored to ensure reaching steady-state plateau before data-logging. Mitochondrial $\mathrm{CO}_{2}$ release in the dark $\left(R_{\mathrm{D}}\right)$ was determined when irradiance was zero.

$\mathrm{NH}$ model and Ye model were fitted to obtain the key quantitative traits defining the $P_{\mathrm{N}}-I$ curves, using the Photosynthesis Model Simulation Software (PMSS) (http://photosynthetic.sinaapp.com, Jinggangshan University, Ji'an). The effects of parameter values ( $\theta$ for $\mathrm{NH}$ model; $\beta$ and $\gamma$ for Ye model) on model simulations were evaluated, using different values of $\theta(1.00,0.75,0.50$, and $0.25)$ for $\mathrm{NH}$ model and different values of $\beta(0,0.00005$, 0.00015 , and $\left.0.0003 \mathrm{~m}^{2} \mathrm{~s} \mu \mathrm{mol}^{-1}\right)$ and $\gamma(0.001,0.002$, 0.003 , and $\left.0.004 \mathrm{~m}^{2} \mathrm{~s} \mu \mathrm{mol}^{-1}\right)$ for Ye model - all with pre-set values of $\alpha\left(0.05 \mu \mathrm{mol} \mu \mathrm{mol}^{-1}\right), P_{\text {Nmax }}(32 \mu \mathrm{mol}$ $\left.\mathrm{m}^{-2} \mathrm{~s}^{-1}\right)$, and $R_{\mathrm{D}}\left(3 \mu \mathrm{mol} \mathrm{m} \mathrm{m}^{-2} \mathrm{~s}^{-1}\right)$.

Statistical analysis: All statistical tests were performed using the statistical package SPSS 18.5 statistical software (SPSS, Chicago, IL). The analysis of variance (ANOVA) was used to assess cultivar effects. Tukey's a posteriori test was conducted to test whether there were significant differences between fitted and measured values of quantitative traits. Goodness of fit of the mathematical model to experimental observations was assessed using the coefficient of determination $\left(R^{2}=1-\mathrm{SSE} / \mathrm{SST}\right.$, where SST is the total sum of squares and SSE is the error sum of squares).

\section{Results}

Performances of two models over light-limited, lightsaturated, and photoinhibitory regions: At the lightlimited region, the increase of $I$ led to an immediate and rapid increase of $P_{\mathrm{N}}$ for all three cultivars - until reaching the cultivar-specific $P_{\mathrm{Nmax}}$ and the corresponding $I_{\text {sat }}$ (Fig. $1 A-C$, Table 1). $P_{\mathrm{Nmax}}$ and $I_{\text {sat }}$ were the highest for Wufengyou1326 and the lowest for JR1326 (Table 1). The $P_{\mathrm{N}}-I$ curve of JR1326 exhibited the most distinct separation among light-limited, light-saturated, and photoinhibitory regions (Fig. $1 A-C$ ). Overall, both NH model and Ye model showed high goodness of fit (Fig. $1 A-C$, Table 1). NH model can characterize $P_{\mathrm{N}}-I$ curve within the light-limited region - except $0-50 \mu$ mol(photon) $\mathrm{m}^{-2} \mathrm{~s}^{-1}-$ and the light-saturated region before reaching $I_{\text {sat. }}$ NH model can neither generate $I_{\text {sat }}$ value due to the model's asymptotic function, nor reproduce the $P_{\mathrm{N}}-I$ curve where the light intensity reached $I_{\text {sat }}$ (when $P_{\mathrm{N}}$ reached $\left.P_{\text {Nmax }}\right)$ and surpassed $I_{\text {sat }}$ (when photoinhibition occurred). 


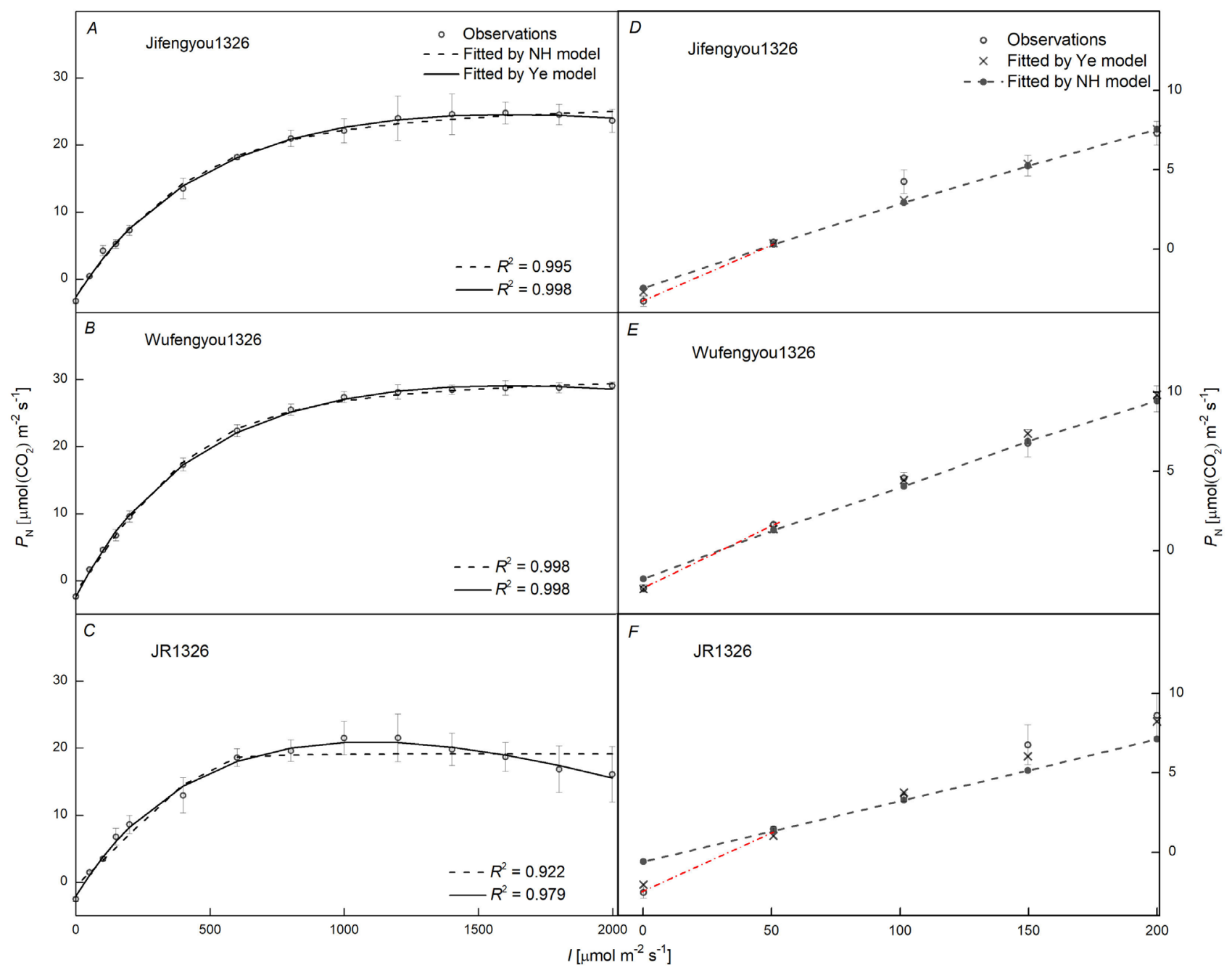

Fig. 1. Light-response curves of photosynthesis at the $I$ range from 0 to $2,000 \mu \mathrm{mol} \mathrm{m}{ }^{-2} \mathrm{~s}^{-1}(A-C)$ and from 0 to $200 \mu \mathrm{mol} \mathrm{m}^{-2} \mathrm{~s}^{-1}(D-F)$ for three rice cultivars - Jifengyou1326 $(A, D)$, Wufengyou1326 $(B, E)$, and JR1326 $(C, F)$. In each subplot, the values are means \pm standard errors $(n=3)$. In subplots $D, E$, and $F$, the black dash line connects the five $P_{\mathrm{N}}$ values fitted by the $\mathrm{NH}$ model respectively at $0,50,100,150$, and $200 \mu \mathrm{mol} \mathrm{m} \mathrm{s}^{-1}$, and the red dash line connects the two $P_{\mathrm{N}}$ observations respectively at 0 and $50 \mu \mathrm{mol} \mathrm{m} \mathrm{m}^{-2} \mathrm{~s}^{-1}$. The horizontal dash dot line indicates when $P_{\mathrm{N}}$ equals to zero.

At $I$ levels between 0 and $200 \mu \operatorname{mol}\left(\right.$ photon) $\mathrm{m}^{-2} \mathrm{~s}^{-1}$, the NH model fitted a nearly linear $P_{\mathrm{N}}-I$ response for all three rice cultivars, where the actual light-response curves were non-linear (Fig. $1 D-F$ ). This bias was paralleled with a notable underestimation of $R_{\mathrm{D}}$ for Jifengyou 1326 (not significant), Wufengyou1326 (not significant), and JR1326 $(P<0.05)$ (Fig. $1 D-F$, Table 1). At the lightsaturated region, $\mathrm{NH}$ model overestimated $P_{\mathrm{Nmax}}$ for Jifengyou1326 (not significant) and Wufengyou1326 $(P<0.05)$, and failed to represent the $P_{\mathrm{Nmax}}$ observation for JR1326 (Fig. $1 A-C$, Table 1). At the photoinhibitory region (i.e., beyond cultivar-specific $I_{\text {sat }}$ ), the fitted curves by NH model consistently deviated from the observations, without representing the decline of $P_{\mathrm{N}}$ at all (Fig. $1 D-F$ ). Ye model characterized the $P_{\mathrm{N}}-I$ curve over light-limited, light-saturated, and photoinhibitory regions very well for all cultivars (Fig. 1, Table 1), and returned accurate values of quantitative traits $\left(e . g ., R_{\mathrm{D}}, I_{\text {sat }}, P_{\mathrm{Nmax}}, I_{\mathrm{c}}\right)$ that were in high agreement with the cultivar-specific values determined from experimental observations over $I$ levels from 0 to 2,000 $\mu$ mol(photon) $\mathrm{m}^{-2} \mathrm{~s}^{-1}$ (Table 1). When fitting $\mathrm{NH}$ model and Ye model to all $P_{\mathrm{N}}-I$ observations by grouping three rice cultivars together, Ye model also showed lower $S S E$ and higher $R^{2}$ - indicating its better performance than NH model (Table 2).

Effects of parameter values on model simulations: For NH model, the shape of function was exclusively defined by convexity of the curve $(\theta)$ when $P_{\text {Nmax }}, \alpha$, and $R_{\mathrm{D}}$ were determined beforehand (Fig. $2 A$ ). At the extreme scenario when $\theta=1, P_{\mathrm{N}}=\alpha I-R_{\mathrm{D}}$ when $\alpha I<P_{\mathrm{Nmax}}$, and $P_{\mathrm{N}}=P_{\mathrm{Nmax}}-R_{\mathrm{D}}$ when $\alpha I>P_{\mathrm{Nmax}}$ (Eq. 1; Fig. $2 A$ ). No simulation exhibited photoinhibition at high $I$ levels (Fig. 2A). For Ye model, the shape of function were defined 


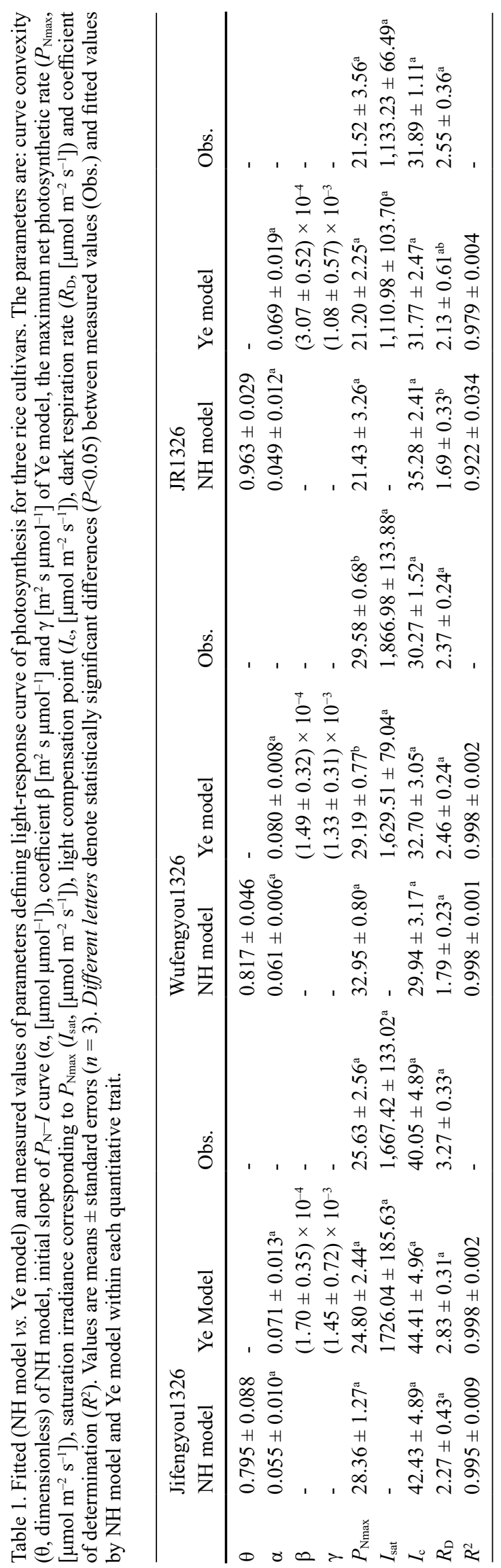

Table 2. The error sum of squares (SSE) and coefficient of determination $\left(R^{2}\right)$ of fitting $\mathrm{NH}$ model and Ye model to all lightresponse of photosynthesis observations by grouping three rice cultivars together $(n=9)$.

\begin{tabular}{lll}
\hline & NH model & Ye model \\
\hline SSE & $25.35 \pm 8.35$ & $11.34 \pm 2.57$ \\
$R^{2}$ & $0.971 \pm 0.014$ & $0.989 \pm 0.003$ \\
\hline
\end{tabular}

by both the photoinhibition coefficient $(\beta)$ and saturation coefficient $(\gamma)$ (Fig. 2B,C). The value of $\beta$ largely defined the photoinhibitory region of the curves (Fig. $2 B$ ). When $\beta=0$, the shape of function degenerated to be a rectangular hyperbolic function (Fig. 2B).

\section{Discussion}

Using a model-observation comparison approach, this study contrasted the performances of Ye model and NH model against experimental observations at cultivarspecific leaf-scale $P_{\mathrm{N}}-I$ responses over a wide range of $I$ levels. The results draw caution on the limitations of the widely used $\mathrm{NH}$ model, in particular: (1) the rarely reported underestimation of $R_{\mathrm{D}}$ (Oryza sativa, cv. JR1326), (2) the widely reported overestimation of $P_{\mathrm{Nmax}}$ (Oryza sativa, cv. Wufengyou1326), and (3) the widely reported but rarely resolved failure in reproducing the photoinhibitory response when $I$ surpassed the cultivar-specific $I_{\text {sat }}$ (all three cultivars).

The results demonstrate that Ye model can address the above limitations of NH model very well. This study highlighted the robustness of Ye model in accurately characterizing the cultivar-specific $P_{\mathrm{N}}-I$ curves, contributing to our understanding of leaf-scale modelling of $P_{\mathrm{N}}-I$ relations, especially in (1) reproducing the curve over low $I$ levels [i.e., $0-50 \mu$ mol(photon) $\mathrm{m}^{-2} \mathrm{~s}^{-1}$ ] and photoinhibitory region (i.e., beyond $I_{\text {sat }}$ ) and (2) fitting key quantitative traits defining the curve (e.g., $\alpha, R_{\mathrm{D}}, P_{\mathrm{Nmax}}$, $I_{\mathrm{c}}$, and $\left.I_{\mathrm{sat}}\right)$. These limitations of $\mathrm{NH}$ model at the leaf scale, if ignored, will arise uncertainties when modelling large-scale irradiance-driven vegetation fluxes (e.g., $\left.R_{\mathrm{D}}\right)$. The robustness of Ye model in reproducing the $P_{\mathrm{N}}-I$ response - in comparison with models widely used for microalgae - has been validated also for a collection of freshwater and marine microalgae species (Yang et al. 2020). These findings suggest Ye model can be applied for species from very different light habitats.

We conclude that Ye model is a robust tool to quantify the photosynthesis capacity of plants across a wide range of ambient $I$ levels. The accurate and simple estimate of cultivar-specific quantitative traits (e.g., $\alpha, R_{\mathrm{D}}, P_{\mathrm{Nmax}}, I_{\mathrm{c}}$, and $\left.I_{\text {sat }}\right)$ by the Ye model highlights the potential for which should be incorporated within models at whole-plant and ecosystem scales. This study highlights the significance of Ye model for breeders, physiologists, and modelers helping them obtain key quantitative traits defining the plant $P_{\mathrm{N}}-I$ responses across light-limited, light-saturated, and photoinhibitory $I$ regions. Further studies may work 


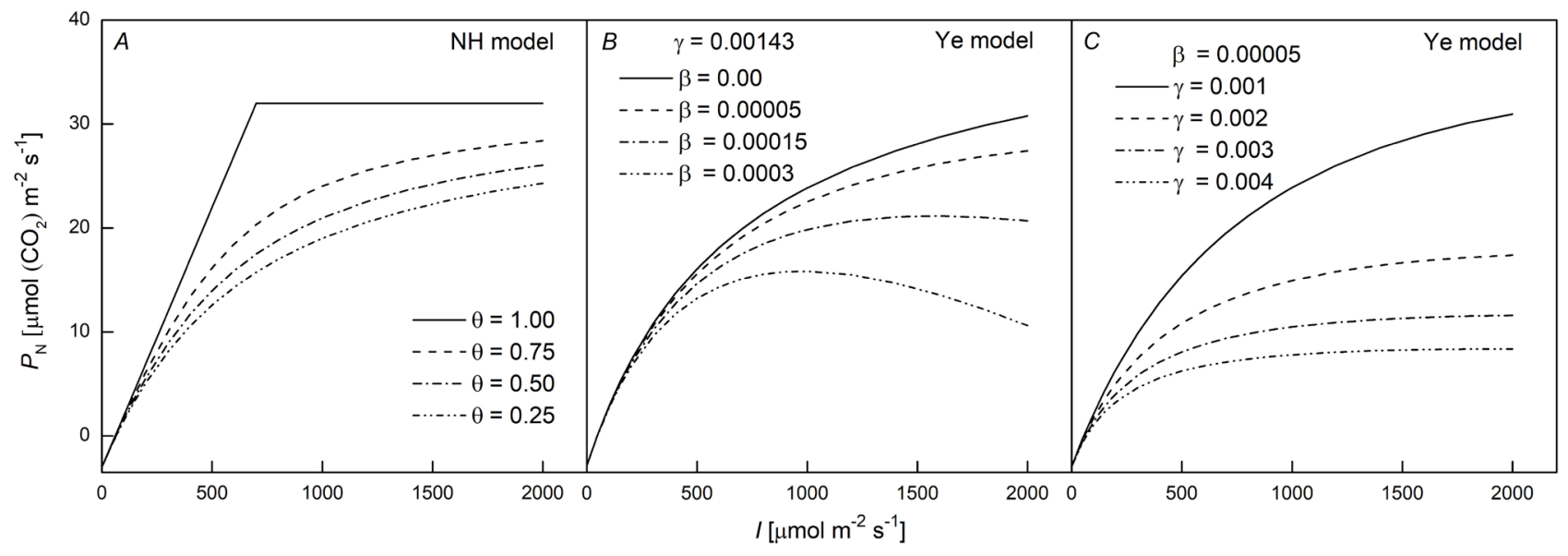

Fig. 2. Effects of parameter values on model simulations $(\theta-$ curve convexity for NH model; $\beta$ - photoinhibition coefficient and $\gamma$-saturation coefficient for Ye model). In subplots $A-C, \alpha=0.05 \mu \mathrm{mol} \mu \mathrm{mol}^{-1}, P_{\mathrm{Nmax}}=32 \mu \mathrm{mol} \mathrm{m}^{-2} \mathrm{~s}^{-1}$, and $R_{\mathrm{D}}=3 \mu \mathrm{mol} \mathrm{m} \mathrm{m}^{-2} \mathrm{~s}^{-1}$, and $P_{\mathrm{N}}-I$ curves were generated using NH model with different values of $\theta(1.00,0.75,0.50$, and 0.25$)(A)$, using Ye Model with different values of $\beta\left(0,0.00005,0.00015\right.$, and $\left.0.0003 \mathrm{~m}^{2} \mathrm{~s} \mu \mathrm{mol}^{-1}\right)$ when $\gamma=0.00143 \mathrm{~m}^{2} \mathrm{~s} \mu \mathrm{mol}^{-1}(B)$, and using Ye model with different values of $\gamma\left(0.001,0.002,0.003\right.$, and $\left.0.004 \mathrm{~m}^{2} \mathrm{~s} \mu \mathrm{mol}^{-1}\right)$ when $\beta=0.00005 \mathrm{~m}^{2} \mathrm{~s} \mu \mathrm{mol}^{-1}(C)$.

on (1) evaluating the performance of Ye model against observations for species of different plant functional type membership and/or climatic origin, (2) characterizing leaf $P_{\mathrm{N}}-I$ relations when plants are concurrently stressed by other environmental drivers, and (3) exploring how to drive the scaling of realistic $P_{\mathrm{N}}-I$ relations from leaves to individual plants and terrestrial ecosystems.

\section{References}

Aspinwall M.J., King J.S., McKeand S.E., Domec J.-C.: Leaflevel gas-exchange uniformity and photosynthetic capacity among loblolly pine (Pinus taeda L.) genotypes of contrasting inherent genetic variation. - Tree Physiol. 31: 78-91, 2011.

Baly E.C.: The kinetics of photosynthesis. - P. Roy. Soc. Lond. B Bio. 117: 218-239, 1935.

Bassman J.H., Zwier J.C.: Gas exchange characteristics of Populus trichocarpa, Populus deltoides and Populus trichocarpa $\times$ P. deltoides clone. - Tree Physiol. 8: 145-159, 1991.

Bellucco V., Marras S., Grimmond C.S.B. et al.: Modelling the biogenic $\mathrm{CO}_{2}$ exchange in urban and non-urban ecosystems through the assessment of light-response curve parameters. Agr. Forest Meteorol. 236: 113-122, 2017.

Calama R., Puértolas J., Madrigal G., Pardos M.: Modeling the environmental response of leaf net photosynthesis in Pinus pinea L. natural regeneration. - Ecol. Model. 251: 9-21, 2013.

dos Santos Jr. U.M., de Carvalho Gonçalves J.F., Fearnside P.M.: Measuring the impact of flooding on Amazonian trees: photosynthetic response models for ten species flooded by hydroelectric dams. - Trees 27: 193-210, 2013.

Farquhar G.D., von Caemmerer S., Berry J.A.: A biochemical model of photosynthetic $\mathrm{CO}_{2}$ assimilation in leaves of $\mathrm{C}_{3}$ species. - Planta 149: 78-90, 1980.

Gomes F.P., Oliva M.A., Mielke M.S. et al.: Photosynthetic irradiance-response in leaves of dwarf coconut palm (Cocos nucifera L. 'nana', Araceae): Comparison of three models. Sci. Hortic.-Amsterdam 109: 101-105, 2006.

Hanson D.T., Stutz S.S., Boyer J.S.: Why small fluxes matter: the case and approaches for improving measurements of photosynthesis and (photo) respiration. - J. Exp. Bot. 67: 3027-3039, 2016.

Ježilová E., Nožková-Hlaváčková V., Duchoslav M.: Photosynthetic characteristics of three ploidy levels of Allium oleraceum L. (Amaryllidaceae) differing in ecological amplitude. - Plant Spec. Biol. 30: 212-224, 2015.

Keenan T.F., Niinemets Ü.: Global leaf trait estimates biased due to plasticity in the shade. - Nat. Plants 3: 16201, 2017.

Knapp A.K., Smith W.K.: Stomatal and photosynthetic responses during sun/shade transitions in subalpine plants: influence on water use efficiency. - Oecologia 74: 62-67, 1987.

Knapp A.K., Smith W.K.: Stomatal and photosynthetic responses to variable sunlight. - Physiol. Plantarum 78: 160-165, 1990.

Koyama K., Kikuzawa K.: Geometrical similarity analysis of photosynthetic light response curves, light saturation and light use efficiency. - Oecologia 164: 53-63, 2010.

Leakey A.D.B., Uribelarrea M., Ainsworth E.A. et al.: Photosynthesis, productivity, and yield of maize are not affected by open-air elevation of $\mathrm{CO}_{2}$ concentration in the absence of drought. - Plant Physiol. 140: 779-790, 2006.

Liu S., Liu W.Y., Shi X.M. et al.: Dry-hot stress significantly reduced the nitrogenase activity of epiphytic cyanolichen. Sci. Total Environ. 619-620: 630-637, 2018.

Lobo F.D.A., Barros M.P.D., Dalmagro H.J. et al.: Fitting net photosynthetic light-response curves with Microsoft Excel a critical look at the models. - Photosynthetica 51: 445-456, 2013.

Martínez-García E., Rubio E., García-Morote F.A. et al.: Net ecosystem production in a Spanish black pine forest after a low burn-severity fire: Significance of different modelling approaches for estimating gross primary production. - Agr. Forest Meteorol. 246: 178-193, 2017.

Mayoral C., Calama R., Sánchez-González M., Pardos M.: Modelling the influence of light, water and temperature on photosynthesis in young trees of mixed Mediterranean forests. New Forest. 46: 485-506, 2015.

Messinger M.S., Buckley T.N., Mott K.A.: Evidence for involvement of photosynthetic processes in the stomatal response to $\mathrm{CO}_{2}$. - Plant Physiol. 140: 771-778, 2006.

Ogawa K.: Mathematical consideration of the pipe model theory in woody plant species. - Trees 29: 695-704, 2015. 
Ögren E., Evans J.R.: Photosynthetic light response curves: 1. The influence of $\mathrm{CO}_{2}$ partial pressure and leaf inversion. Planta 189: 182-190, 1993.

Park K.S., Bekhzod K., Kwon J.K., Son J.E.: Development of a coupled photosynthetic model of sweet basil hydroponically grown in plant factories. - Hortic. Environ. Biote. 57: 20-26, 2016.

Poirier-Pocovi M., Lothier J., Buck-Sorlin G.: Modelling temporal variation of parameters used in two photosynthesis models: influence of fruit load and girdling on leaf photosynthesis in fruit-bearing branches of apple. - Ann. Bot.-London 121: 821-832, 2018.

Posada J.M., Lechowicz M.J., Kitajima K.: Optimal photosynthetic use of light by tropical tree crowns achieved by adjustment of individual leaf angles and nitrogen content. Ann. Bot.-London 103: 795-805, 2009.

Prado C.H.B.A., de Moraes J.A.P.V.: Photosynthetic capacity and specific leaf mass in twenty woody species of Cerrado vegetation under field condition. - Photosynthetica 33: 103$112,1997$.

Quiroz R., Loayza H., Barreda C. et al.: Linking processbased potato models with light reflectance data: Does model complexity enhance yield prediction accuracy? - Eur. J. Agron. 82: 104-112, 2017.

Raj R., Hamm N.A.S., van der Tol C., Stein A.: Uncertainty analysis of gross primary production partitioned from net ecosystem exchange measurements. - Biogeosciences 13: 1409-1422, 2016.

Ralph P.J., Gademann R.: Rapid light curves: A powerful tool to assess photosynthetic activity. - Aquat. Bot. 82: 222-237, 2005.

Shimada A., Kubo T., Tominaga S., Yamamoto M.: Effect of temperature on photosynthesis characteristics in the passion fruits 'Summer Queen' and 'Ruby Star'. - Horticult. J. 86: 194-199, 2017.

Smith E.L.: Photosynthesis in relation to light and carbon dioxide. - P. Natl. Acad. Sci. USA 22: 504-511, 1936.

Smith W.K., Knapp A.K., Reiners W.A.: Penumbral effects on sunlight penetration in plant communities. - Ecology 70: 1603-1609, 1989.

Thornley J.H.M.: Mathematical Models in Plant Physiology. Pp. 86-110. Academic Press, London 1976.

Thornley J.H.M.: Dynamic model of leaf photosynthesis with acclimation to light and nitrogen. - Ann. Bot.-London 81: 421-430, 1998.

Wang M.J., Xie B.Z., Fu Y.M. et al.: Effects of different elevated
$\mathrm{CO}_{2}$ concentrations on chlorophyll contents, gas exchange, water use efficiency, and PSII activity on $\mathrm{C}_{3}$ and $\mathrm{C}_{4}$ cereal crops in a closed artificial ecosystem. - Photosynth. Res. 126: 351-362, 2015.

Wang N.N., Huang Q.J., Sun J.R. et al.: Shade tolerance plays an important role in biomass production of different poplar genotypes in a high-density plantation. - Forest Ecol. Manag. 331: 40-49, 2014.

Wargent J.J., Elfadly E.M., Moore J.P., Paul N.D.: Increased exposure to UV-B radiation during early development leads to enhanced photoprotection and improved long-term performance in Lactuca sativa. - Plant Cell Environ. 34: 1401-1413, 2011.

Webb W.L., Newton M., Starr D.: Carbon dioxide exchange of Alnus rubra: a mathematical model. - Oecologia 17: 281-291, 1974.

Xu Z.F., Hu T.X., Zhang Y.B.: Effects of experimental warming on phenology, growth and gas exchange of treeline birch (Betula utilis) saplings, Eastern Tibetan Plateau, China. - Eur. J. For. Res. 131: 811-819, 2012b.

Xu Z.F., Yin H.J., Xiong P. et al.: Short-term responses of Picea asperata seedlings of different ages grown in two contrasting forest ecosystems to experimental warming. - Environ. Exp. Bot. 77: 1-11, 2012a.

Yang X.L., Liu L.H., Yin Z.K. et al.: Quantifying photosynthetic performance of phytoplankton based on photosynthesisirradiance response models. - Environ. Sci. Eur. 32: 24, 2020.

Yao X., Zhou H., Zhu Q. et al.: Photosynthetic response of soybean leaf to wide light-fluctuation in maize-soybean intercropping system. - Front. Plant Sci. 8: 1695, 2017.

Ye Z.P.: A new model for relationship between irradiance and the rate of photosynthesis in Oryza sativa. - Photosynthetica 45: 637-640, 2007.

Ye Z.P., Suggett J.D., Robakowski P., Kang H.J.: A mechanistic model for the photosynthesis-light response based on the photosynthetic electron transport of photosystem II in $\mathrm{C}_{3}$ and $\mathrm{C}_{4}$ species. - New Phytol. 199: 110-120, 2013.

Yu Q., Liu Y.F., Liu J.D., Wang T.D.: Simulation of leaf photosynthesis of winter wheat on Tibet Plateau and in North China Plain. - Ecol. Model. 55: 205-216, 2002.

Zhu X.G., Ort D.R., Whitmarsh J., Long S.P.: The slow reversibility of photosystem II thermal energy dissipation on transfer from high to low light may cause large losses in carbon gain by crop canopies: a theoretical analysis. - J. Exp. Bot. 55: 1167-1175, 2004.

(C) The authors. This is an open access article distributed under the terms of the Creative Commons BY-NC-ND Licence. 